\title{
EL NUEVO NUEVO VIEJO OESTE. UN PAISAJE SIN LUGAR
}

\author{
Carlos Santamarina-Macho
}

El oeste es un mito tradicionalmente estadounidense que tiene entre sus rasgos distintivos la identificación con un determinado paisaje, elemento central en la definición de su significado. Sin embargo, el paisaje del oeste, como construcción cultural, se ha ido transformando a lo largo del siglo XX, asociándose a diferentes territorios, reales e imaginados. El artículo realiza un recorrido por algunas de sus principales reinterpretaciones, desde las primeras formalizaciones ofrecidas por la literatura y las artes de finales del siglo XIX hasta los actuales imaginarios reproducidos por el cine y la televisión. El oeste americano se muestra como un instrumento que sintetiza una determinada interpretación del territorio, la cultura y la sociedad norteamericana, configurando un modo particular de mirar y dotar de sentido a la realidad con la capacidad de adaptarse a diferentes contextos espaciales y temporales.

Palabras clave: Oeste norteamericano, paisaje construido, lugar, fotografía Keywords: American West, Man-made Landscape, Place, Photography

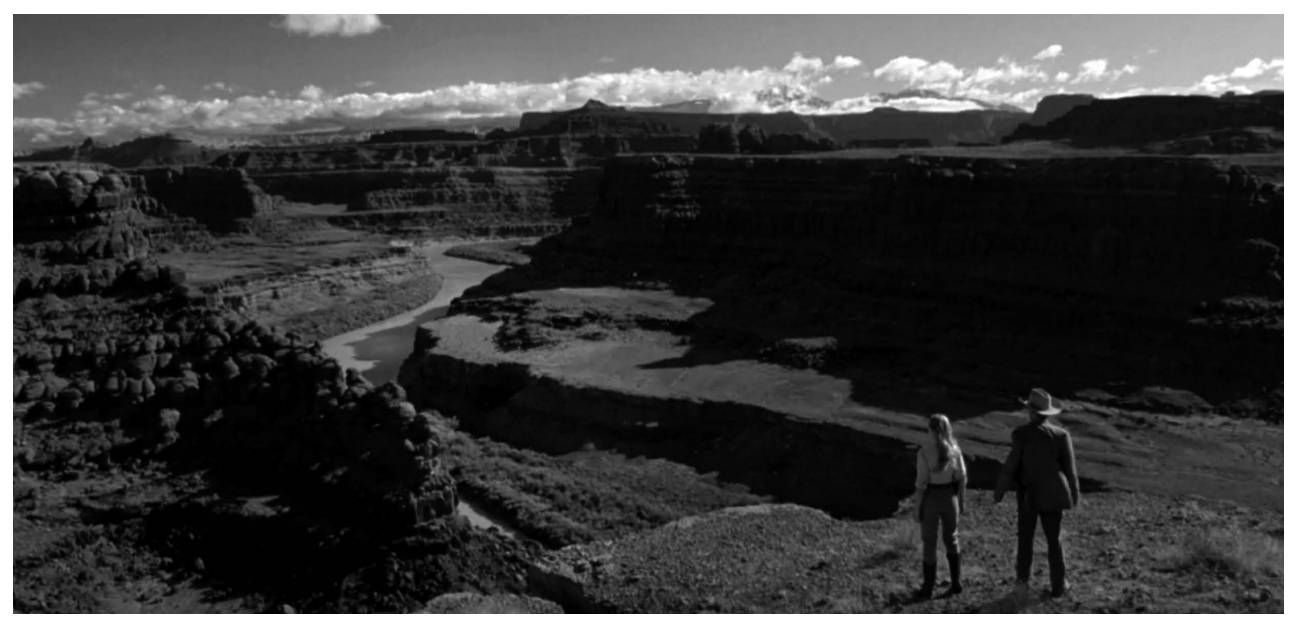

Estamos asistiendo en la actualidad a un renacer del interés por las historias del oeste americano. El pasado año ha sido particularmente prolífico en la producción de ficciones basadas en el western, gracias a series de sustrato histórico como The Frontier, documentales como The American West, distopías futuristas como WestWorld, o grandes producciones como The Revenant que, siguiendo la estela de películas como Dead Man, True Grit ${ }^{1}$ o The Hateful Eight, o incluso de series como Deadwood o Breaking Bad, esta última una suerte de neo western, han recuperado y reinterpretado distintos aspectos de los mitos de la colonización y conquista americana.

La revisión de este tipo de géneros, que basculan entre lo histórico y lo mítico, no resulta infrecuente. Pero al contrario que el péplum o los Space Opera, cuyo resurgir ha sido más tímido, el western, arquetipo de una ficción eminentemente norteamericana, ha irrumpido con extraordinaria fuerza no solo en su contexto de origen, aquel en el que cobra verdadero significado cultural, sino también fuera del mismo ${ }^{2}$. Incluso el Museo Thyssen-Bornemisza ha dedicado una reciente exposición a esta temática ${ }^{3}$ aparentemente distante de los objetos principales de la institución. Muestra a la que habría que sumar el creciente interés generado por un tipo de fotografía del paisaje estadounidense apoyada a partes iguales en la recreación y el cuestionamiento de los mitos de frontera, que puede ejemplificarse, entre otras, con la también reciente celebración de la primera retrospectiva europea sobre la obra de Lewis Bal$\mathrm{tz}^{4} \mathrm{o}$ la recuperación de las fotografías decimonónicas pertenecientes a la colección Sorolla en la exposición Watkins, el paisaje de Estados Unidos.
Fig. 1. Fotograma de la serie WestWorld (HBO), mostrando a tres de sus protagonistas.
1. La más directa, pero no la primera, aproximación de los hermanos Coen a este universo, quienes ya habían utilizado algunos de sus recursos en el neo-western No Country for Old Men, y que repetirán en la futura serie The Ballad of Buster Scruggs.

2. No solo desde la perspectiva de su éxito comercial, sino también de la propia creación de productos sustentados en estos mitos, como la película sueca The Salvation o, de forma más tangencial, la española Una noche en el Viejo México, por citar solo dos ejemplos recientes.

3. BLANCO, Miguel Ángel, et al., La ilusión del lejano oeste: Museo Thyssen-Bornemisza, 3-11-2015, 7-2-2016. Fundación Colección Thyssen-Bornemisza, Madrid, 2015. La exposición realizaba un recorrido desde algunas de las pinturas de las escuelas paisajísticas americanas hasta experiencias artísticas contemporáneas inspiradas en el universo del western, con una destacada muestra de representaciones de las culturas nativas americanas a través de la obra pictórica de George Catlin y la fotográfica de Edward S. Curtis.

4. BALTZ, Lewis y STAHEL Urs, Lewis Baltz, Fundación MAPFRE, Madrid, 2017. 
5. ASTRE, Georges-Albert y Albert-Patrick HOARAU, El universo del Western, Fundamentos, Madrid, 1997, p. 75.

6. PAVESE, Cesare, "Del mito, del símbolo y de las cosas", en La literatura americana y otros ensayos. Random House Mondadori, S.A., Barcelona, 2010. Pavese no se refiere en este ensayo específicamente al paisaje norteamericano, $\mathrm{si}$ bien el contexto de los escritos en el que se inserta ayuda a vincularlo al mismo,

7. TURNER, Frederick Jackson, "The significance of the Frontier en American History", en Frederick Jackson Turner: Wisconsin's Historian of the Frontier, State Historical Society of Wisconsin, Madison, 1986.

8. James Fenimore Cooper, quizá el primer gran novelista auténticamente americano, se inspira no obstante en arquetipos previos como el American Farmer descrito por Hecto St. John de Crèvecœur en Letters from an American Farmer. Dover Publications, London, 2005. Véase CUENCA, Carme Manuel, La literatura de Estados Unidos desde sus orígenes hasta la Primera Guerra Mundial, Editorial Síntesis, S.A., Madrid, 2006.

9. Son las historias escritas en las primeras décadas del siglo $X X$ por Eugene Manlove Rhodes, Frederick Schiller Faust 0 Pearl Zane Gray, entre otros, a los que seguirían ya a mediados de siglo Frank Gruber o Dorothy M. Johnson.

10. La representación de las poblaciones nativas americanas ya era frecuente, con una perspectiva etnográfica, desde mediados del siglo XIX, quedando definidas por los trabajos de Karl Bodmer, George Catlin o Alfred Jacob Miller. Las representaciones de comienzos del siglo XX, como las de Charles M. Russell, se alimentarán de estos antecedentes, pero enfatizando la confrontación cultural entre colonos y nativos.

11. Hay algunas excepciones, como las ilustraciones de Alfred Jacob Miller, cuyos retratos de las comunidades indias se apoyan con frecuencia en un marco paisajístico, o yéndonos más atrás en el tiempo, los cuadros de Charles Caleb Binghan. En ambos casos se trata, no obstante, de territorios idealizados más que reales.

12. Véase HOBSBAWM, Eric, "El 'vaquero' de Estados Unidos: ¿Un mito internacional?" en Un tiempo de rupturas. Sociedad y cultura en el siglo XX, Crítica, Barcelona, 2013. Hobsbawm señala no solo que la figura histórica del vaquero no fue particularmente relevante en la historia americana sino que tampoco lo fueron algunos de los escenarios clásicos de sus aventuras.

13. James Jackson Jarves, en "The Art-Idea: Sculpture, Painting and Architecture in America" (1864), citado en GRANT, Susan-Mary, Historia de los Estados Unidos de América. Akal, Tres Cantos, Madrid, 2014, p. 241.

14. COSGROVE, Denis E., Social formation and symbolic landscape. Croom Helm, Londres, 1984, pp. 161-88.

15. EMERSON, Ralph Waldo, Ensayo sobre la naturaleza. Ediciones de Baile del Sol, Tenerife, 2000.

16. EMERSON, Ralph Waldo, "El poeta" en Obra ensayística, Artemisa Ediciones, Valencia, 2010.

17. Véase AVERY, Kevin J., "A historiography of the Hudson River School” en O'NEILL, John P., en American Paradise. The World of the Hudson River School, The Metropolitan Museum of Art, New York, 1987.

18. DURAND, Asher Brown, et al., The American landscape, Elam Bliss, New York, 1830, p. 3
El western es, en buena medida, el resultado de la construcción de un determinado modelo social y cultural, de unos arquetipos que resultan no solo atractivos sino también, por su condición icónica, extraordinariamente versátiles para la narración de historias. Sin embargo, uno de los principales atractivos del género no se encuentra ni en sus personajes ni en sus avatares, sino en el propio escenario en el que los mismos se desenvuelven, en un territorio también icónico, y al mismo tiempo estereotipado, que dota de sentido y adquiere un papel protagonista en las narraciones (Fig. 1). El propio John Ford decía que "la cosa descrita con más cuidado en el 'western' es el lugar. Pienso que ustedes pueden decir que la verdadera estrella de mis 'westerns' ha sido siempre el lugar"s.

No obstante, el oeste y su territorio no es solo un objeto de ficción, ni tampoco una realidad histórica caduca. El western fílmico es la representación ficticia y comercial de un modelo cultural, de raíces míticas, que trasciende los límites de la pantalla impregnando diversos aspectos de la realidad, material e inmaterial, estadounidense. Es esa relación entre la América real y la imaginada, visualizada a través de su territorio y guiada por la idea de "el oeste" la que es objeto de este texto.

Comenzando por la historia de la frontera y su caracterización como mito, y terminando en algunas de las más recientes reinterpretaciones espaciales del oeste, se pretende trazar un discurso paralelo entre ficción y realidad que ayude a comprender cómo lo que comúnmente conocemos como el paisaje del oeste, y su interpretación social, ha ido evolucionando y mutando a lo largo del tiempo para adecuarse a los requerimientos de diferentes contextos históricos. Se aborda así la existencia de un paisaje sin lugar, de una idea del espacio que no pertenece a ningún territorio y a la vez puede pertenecer a todos. De ese paisaje que, como señalaba Cesare Pavese, no es tanto lo singular como lo común y universal, un paisaje que con su indeterminación evoca todos los territorios "y a todos los anima con su escalofrío simbólico".

\section{LA MITIFICACIÓN DEL VIEJO OESTE}

El western como género no es sino una recreación ficticia y estereotipada de un determinado contexto histórico cuya construcción está íntimamente vinculada a unas particulares representaciones visuales de un territorio, a un paisaje. Y hablamos de "un territorio", no de un lugar en concreto o del propio espacio en el que tuvieron lugar los acontecimientos históricos en los que se basa porque, al igual que estos y sus personajes arquetípicos, son más una construcción mítica que una realidad, aunque originalmente estuviesen apoyados en la misma.

El nacimiento del mito del salvaje oeste se produce, al igual que el de la frontera, una vez concluido el proceso histórico de colonización del territorio norteamericano. Y si el segundo encuentra su origen en una revisión romántica del relato ofrecido por el historiador Frederick Jackson Turner en su artículo The significance of the Frontier in American History ${ }^{7}$, el primero surge fundamentalmente del proceso de creación de unas manifestaciones artísticas auténticamente norteamericanas e independientes del legado europeo, en particular literarias y pictóricas, que aunque se inicia en el primer cuarto del siglo XIX eclosionará en los primeros años del siglo XX dando lugar a unos cánones que serán rápidamente absorbidos por la recién nacida cinematografía.

Dos nombres, íntimamente relacionados entre sí, destacan como creadores de este mito moderno. Aunque sus grandes temas, como las ideas del pionero de frontera, del héroe individualista o del conflicto indio, ya habían sido formulados por James Fenimore Cooper a comienzos del siglo XIX ${ }^{8}$, será el novelista Owen Wister, quien con Lin McLean (1897) y, particularmente, The Virginian: A Horseman of the Plains (1902) revitalice las historias fronterizas y asocie a ellas la figura del vaquero, y no del trampero habitual en las narrativas de la primera mitad del XIX, a partir de las cuales comenzará a proliferar un tipo de literatura de aventuras, de no demasiada calidad pero de gran éxito popular?. Por otro lado, el pintor Frederic Remington, amigo de Wister, establece, y en gran medida inventa, las referencias visuales, particularmente las relativas a los personajes y acciones pero no tanto a los escenarios, que años después, con las aportaciones de otros artistas como Charles Marion Russell o Charles Schreyvogel, serán reproducidas por el cine. La historia del oeste como género, que en el contexto cinematográfico se inicia con The great train robery (1903) de Edwin S. Porter, 
es, en gran medida, la de la reinvención y distorsión romántica de una realidad histórica, que iba a poner el foco sobre unos personajes, los vaqueros, y unos temas, como el de las comunidades indias ${ }^{10}$, que ya habían aparecido previamente en las artes estadounidenses, pero también la de la definición de un territorio auténticamente norteamericano. Todo ello resulta representativo de distintos tipos de conflicto, social, cultural y espacial, entre "lo civilizado" y "lo salvaje", que configuran en buena medida una de las esencias de la propia identidad nacional.

Resulta interesante centrarnos en este último aspecto, el territorial, abordado de modo secundario e idealizado en las primeras representaciones visuales del mito ${ }^{11}$, más centradas en los personajes, pero que adquirirá progresivamente un papel de creciente relevancia. La edición ilustrada de Lin McLean (Fig. 2), que recurre a un dibujo de Frederic Remington para mostrar al protagonista pero utiliza indistintamente dibujos y fotografías para situarnos en el escenario natural de la acción, nos ofrece una pista del porqué. Mientras el arquetipo del vaquero, una figura sin apenas relevancia real en la historia norteamericana ${ }^{12}$, debía ser creado, el del paisaje auténticamente estadounidense, sobre el que expresar el conflicto entre hombre y naturaleza, ya estaba plenamente desarrollado y asumido gracias a unas representaciones artísticas del territorio que, como tempranamente reconoció el crítico de arte James Jackson Jarves, constituían, ya a mediados del siglo XIX, "la rama de la pintura enteramente estadounidense, basada en las experiencias y gustos de la gente" ${ }^{13}$. Si el mito territorial existía, resultaba suficiente con recuperar del mismo aquellos elementos que pudiesen ser útiles para localizar las nuevas narrativas, sin importar si las mismas coincidían o no con los hechos históricos representados. Lo importante no era ver el verdadero oeste, sino aquel oeste que podía ser fácilmente reconocido como tal. Y al mismo tiempo también, una vez concluido el proceso colonizador, aquel que pudiese ayudar al gran público a acercarse, físicamente y en su imaginación, a los territorios conquistados.

\section{LA CREACIÓN DEL IMAGINARIO TERRITORIAL DECIMONÓNICO}

El geógrafo Denis Cosgrove afirmaba que el nacimiento de América había sido, por encima de todo, el nacimiento de su paisaje ${ }^{14}$, de un conjunto de ideas y símbolos que, en paralelo a la transformación material del territorio, habían ayudado a configurar una identidad nacional propia y diferenciada. Y es que los Estados Unidos, desde una fase muy temprana de su historia, abordaron ya la construcción de un particular imaginario territorial, que nace casi en paralelo a sus primeras manifestaciones literarias propias, aquellas novelas de James Fenimore Cooper pero también a movimientos intelectuales que vieron en lo territorial, y particularmente en la naturaleza, una de las bases de la joven nación. Es el caso de algunos de los textos de Ralph Waldo Emerson, como Nature ${ }^{15}$, con el que presentó sus primeras intuiciones acerca del papel que la naturaleza podría jugar en la cultura y el arte estadounidense, pero también The Poet, donde reclamaba un arte que exaltase "una vasta geografía [americana que] deslumbra la imaginación"16.

La aparición en torno a 1830 de un conjunto heterogéneo de pintores, agrupados ya en la segunda mitad de siglo bajo la denominación de Hudson River School ${ }^{17}$, que abandonan una representación paisajística idealizada heredada de la tradición europea para centrarse en una fiel a la propia realidad territorial norteamericana, señala el inicio del proceso de creación de un imaginario paisajístico propio que, partiendo del medio pictórico, se irá desarrollando y reproduciendo a través de otros medios visuales como la fotografía o el cine, pero también de su construcción mítica. Porque los pintores de esta escuela, como Thomas Cole o Asher Brown Durand no se limitaron únicamente a convertir aquella realidad territorial en un motivo artístico, sino también a impregnar sus representaciones de determinados valores simbólicos, construyendo unas determinadas conexiones entre el hombre, americano, y su entorno. La llamada que estos, junto con el poeta William Cullen Bryant, hicieron a la realización de "una serie de vistas precisas tan amplias como para ofrecer una idea adecuada del aspecto de nuestros paisajes", en "una nación como la nuestra, rica en toda clase de escenarios naturales" $" 18$ constituye toda una declaración de intenciones para un grupo de artistas cuyos trabajos, no debe olvidarse, se produjeron realmente en un ámbito espacial muy acotado. En este sentido, los pintores de la Hudson River School no pintaron el territorio del oeste, pero sí

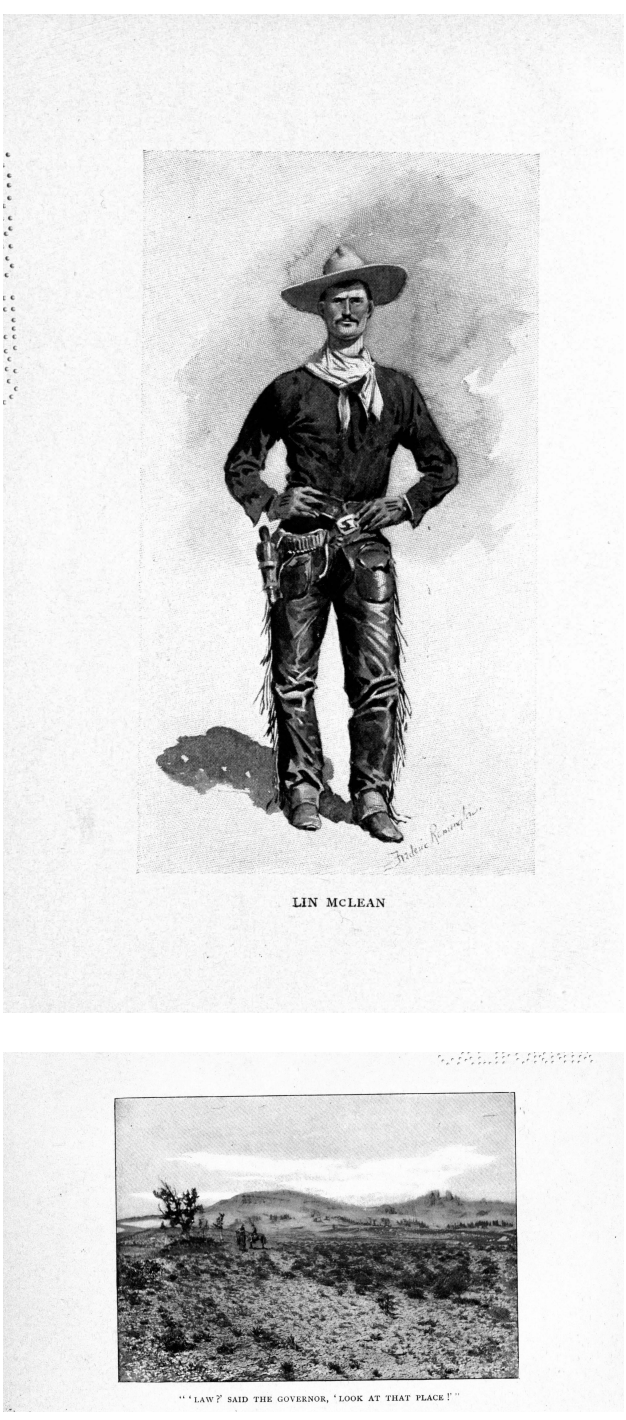

Fig. 2. Páginas interiores de una edición ilustrada de Lin McLean, de Owen Wister, publicada en 1901. Arriba, dibujo del vaquero protagonista realizada por Frederic Remington. Debajo, ilustración del escenario de la acción, el territorio como un personaje más. 


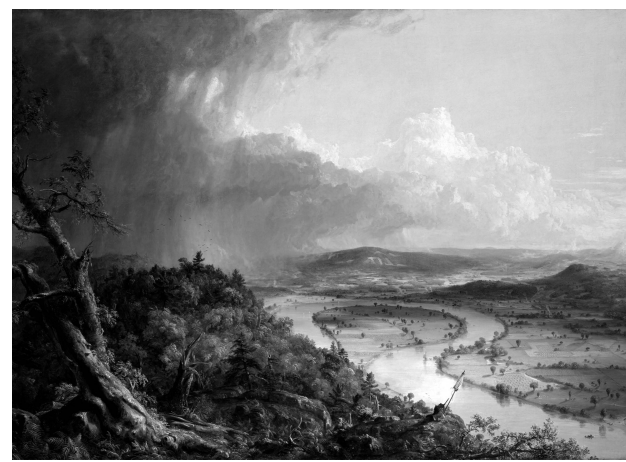

3

Fig. 3. Thomas Cole. The Oxbow (The Connecticut River near Northampton) (1836). (Metropolitan Museum of Art. Recuperada de https://commons.wikimedia.org/wiki/ File:Thomas_Cole,_The_0xbow.jpg).

Fig. 4. Timothy O'Sullivan, "Cañon de Chelle, Walls of the Grand Cañon about 1200 Feet in Height" (1873). (En WHEELER, George Montague. Photographs showing landscapes, geological and other features, of portions of the western territory of the United States, obtained in connection with geographical and geological explorations and surveys west of the 100th meridian, seasons of 1871, 1872, and 1973. War Department. Corps of Engineers. U.S. Army, Washington, ca. 1876)

Fig. 5. Buffalo Bill en Point Sublime (Gran Cañón del Colorado, ca. 1891), recreando el western mítico. (En BUEL, James William. America's Wondeland. A Pictorial and Descriptive History of our Country's Scenic Marvels. John Williams, New York, 1893).

19. COLE, Thomas, "Essay on American Scenery", en American Monthly Magazine (1 (January 1836)), 1836, 1-12.

20. Por ejemplo, las imágenes producidas en el marco de la U.S. Geological Survey West of the 100th Meridian que acompañaron el informe oficial de la misma, WHEELER, George Montague, Report upon United States Geograghical Surveys West of the Hundredth Meridian. Goverment Printing Office, Washington, 1889. fueron utilizadas también para la edición de un libro específico de fotografías, WHEELER, George Montague, Photographs showing landscapes, geolo gical and other features, of portions of the western territory of the United States, obtained in connection with geographical and geological explorations and surveys west of the 100th meridian, seasons of 1871, 1872, and 1973. War Department. Corps of Engineers. U.S. Army, Washington, ca. 1876. E algunos casos la publicación gráfica tuvo incluso una trascendencia superior a la documentación técnica, como en el caso del libro de fotografías de la U.S. Geological Survey of the Territories dirigida por Francis Vandiveer Hayden, y que sirvió expresamente para que Yellowstone fuese declarado como primer Parque Nacional de los Estados Unidos. HAYDEN, Ferdinand Vandeveer, Photographs of the Yellowstone National Park and views in Montana and Wyoming territories, Goverment Printing Office, Washington, 1873.

21. BUEL, James William, America's Wondeland, A Pictorial and Descriptive History of our Country's Scenic Marvels, John Williams, New York, 1893.

22. ASTRE, Georges-Albert y Albert-Patrick HOARAU, El universo del Western. Fundamentos, Madrid, 1997, p. 42. Los autores ejemplifican esta afirmación comparando las narrativas del oeste de John Ford, Anthony Mann y John Huston.

23. Véase HOBSBAWM, Eric, "El 'vaquero' de Estados Unidos: ¿Un mito internacional?” en op. cit.
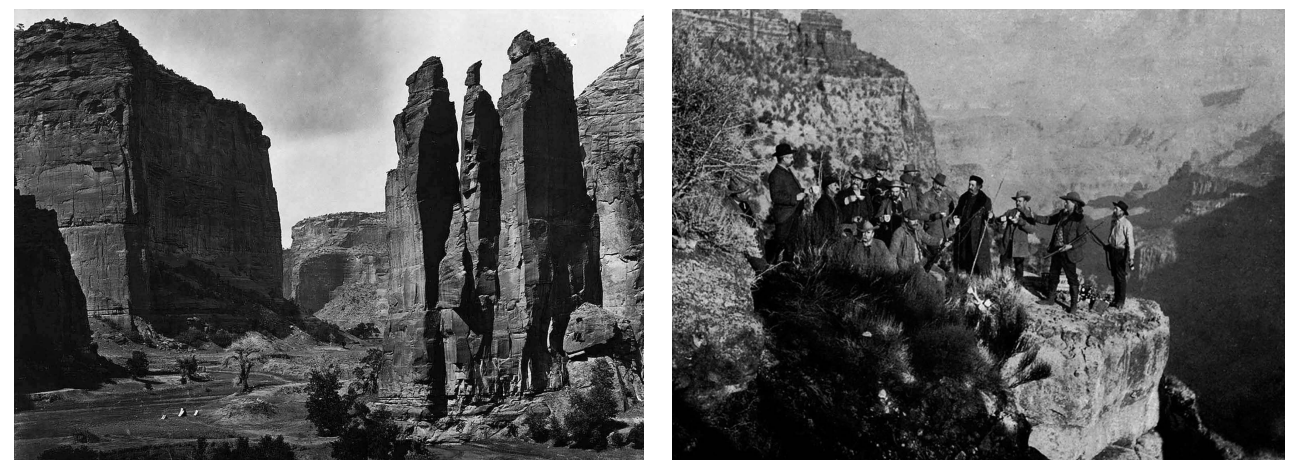

4

5

sentaron las bases acerca de cómo retratarlo (Fig. 3) y, de algún modo, también identificaron qué elementos del mismo podrían ser repositorios de la autenticidad paisajística norteamericana a través de textos como Essay on American Scenery ${ }^{19}$.

Pero si la pintura estableció las reglas para el reconocimiento de este territorio auténticamente norteamericano, será la fotografía la que permita construir verdaderamente ese imaginario visual. Primeramente gracias a los trabajos de documentación de los nuevos territorios conquistados realizados por fotógrafos como Timothy O'Sullivan, Carleton Eugene Watkins, William Henry Jackson, William Bell,... acompañantes indispensables de las expediciones organizadas por la U.S. Geological and Geographical Surveys, aunque también esenciales en las promovidas por las empresas ferroviarias, cuyas imágenes no solo ilustraron informes gubernamentales oficiales (Fig. 4), sino que servían también como mecanismo de información y difusión ${ }^{20}$. Pero sobre todo gracias a la popularización de estas imágenes, cuya demanda por parte de la sociedad se incrementó progresivamente en las últimas décadas del siglo XIX, siendo consumidas en forma de estereografías, carte de visite, o libros como America's Wonderland: Pictorial and Descriptive History of Our Country's Scenic Marvels as Delineated by Pen and Camera, editado por James W. Buel' ${ }^{21}$ (Fig. 5) que ensalzaban las maravillas americanas, contribuyendo a crear un escenario estereotipado para la historia de la colonización. Los territorios fotografiados no hacían sino comunicar, de modo sencillo, algunos de los grandes ideales de una joven sociedad, alimentando el simbolismo de un paisaje del oeste que progresivamente se hacía más mítico y menos real. Las historias del oeste nacidas a comienzos del siglo XX no hicieron otra cosa que incorporar los personajes a este espacio alegórico previamente definido.

\section{LA ADAPTACIÓN DE LA IDEA DEL VIEJO OESTE}

La transformación de aquel territorio real en mítico, lejos de ser una anécdota, constituye un hecho de extraordinaria relevancia en tanto que produce una disociación entre la historia, el lugar en el que esta sucede y su significado cultural, convirtiendo al oeste en una herramienta de comunicación ideológica extraordinariamente flexible, particularmente al posibilitar la vinculación de algunos de sus rasgos, como la personalidad del pionero o el enfrentamiento entre lo civilizado y lo salvaje, a situaciones diferentes a aquellas en las que tuvieron su origen. Esta circunstancia emerge ya en los western de ficción, y particularmente en el cine. Astre y Hoarau afirmaban al respecto que "si el valor mítico del Oeste permanece casi constante, el espacio real del wild west es muy variable. (De ahí que) cada realizador de westerns construya su obra a cierto nivel dentro de una triple realidad: histórica, mítica y geográfica"'22.

El lugar es, en todo caso, un elemento central de la narrativa, incluso el más relevante de todos los que sirven para transmitir la historia, con independencia de su fidelidad a la misma. Porque lo importante era que este fuese capaz de dotar de carácter a los personajes y transmitir unos determinados significados fácilmente reconocibles, aquellos que habían comenzado a ser asociados a imágenes gracias a la pintura y fotografía del siglo anterior. Su trasposición al cine se inicia tempranamente gracias a Thomas Harper Ince, quien creará los primeros escenarios artificiales del oeste, los de aquellas ciudades vaqueras que apenas habían tenido relevancia en la historia americana ${ }^{23}$, pero que a partir de los años treinta se 


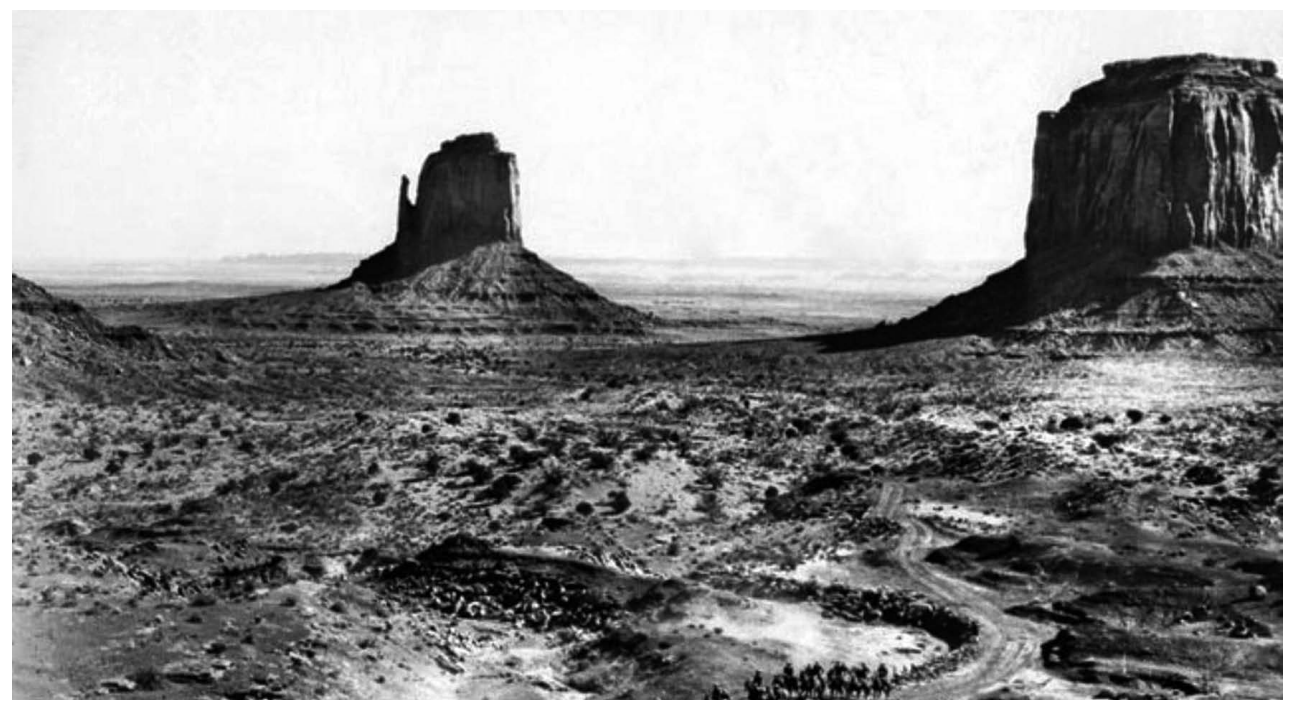

6

harán imprescindibles en todo western ${ }^{24}$. Otros directores como John Ford, más interesados en la fidelidad de la localización, buscaron en la propia naturaleza los escenarios perfectos para sus epopeyas ${ }^{25}$, con independencia también de la trascendencia histórica de los mismos, y encontraron un Monument Valley (Fig. 6) hoy convertido en inconfundible escenario. Aunque quizá la dislocación definitiva entre historia y lugar, preservando el simbolismo del género, sea la surgida ya tardíamente con los spaghetti western de Sergio Leone, que nos harán reconocer América en tierras almerienses, y sin la cual no resultaría posible entender plenamente otros desplazamientos como los asociados a los modernos south westerns, neo westerns, o incluso radicales como los space westerns ${ }^{26}$.

No obstante, esta recreación histórica, simbólica y paisajística del oeste no se limita a la ficción, sino que, como referente cultural, impregna otros aspectos de la realidad social norteamericana y es periódicamente recuperada como mecanismo para abordar la comprensión o gestión de determinados fenómenos utilizando, al igual que el mito, los territorios como base comunicativa. Algo que puede englobarse dentro de un fenómeno de reconocimiento de la existencia de un new west, de la permanencia, aún en el siglo XX y XXI, de algunos de los elementos que definieron cultural y espacialmente la frontera decimonónica.

Esta búsqueda del nuevo oeste, que comienza a ser avalada por las ciencias sociales, históricas y geográficas americanas ${ }^{27}$ a partir de mediados de los años ochenta, tiene sus raíces décadas atrás, y un desarrollo casi paralelo a la configuración del ficticio old west. Ya en los años treinta, por ejemplo, pueden identificarse algunos intentos de redescubrimiento del oeste, como el que llevará a cabo el fotógrafo Edward Weston en su proyecto, avalado por dos becas de la John Simon Guggenheim Memorial Fundation, The making of a series of Photographic Documents of the West (Fig. 7), gracias al que comienza a mostrarse una nueva imagen, territorial pero también social, de este concepto, más realista y coherente con su tiempo que la que ofrecía el mito original ${ }^{28}$.

Es esta condición social, inseparable en cualquier caso del contexto territorial en el que la misma se produce, la que motiva la que será la primera muestra importante de ese "nuevo oeste". Surgirá como una de las respuestas que desde la sociedad y la política norteamericanas se dé al periodo de la Gran Depresión y, de manera específica, a las crisis agrícolas derivadas tanto del marco económico global como de las tormentas de polvo (Dust Bowl) que azotaron el medio oeste a comienzos de la década, desplazando las viejas ideas a un nuevo escenario, que ya no es el de la naturaleza sino una particular reinterpretación del medio agrícola, otro de los grandes mitos territoriales nacionales, que podía erigirse entonces como el renovado soporte de algunos de los valores atribuidos al hombre de frontera, de aquello que algunos denominaron The True American Way en contraposición al consumista American Way of Life dominante en los felices años veinte. Como lo expresaba Lawrence W. Levine ${ }^{29}$ :

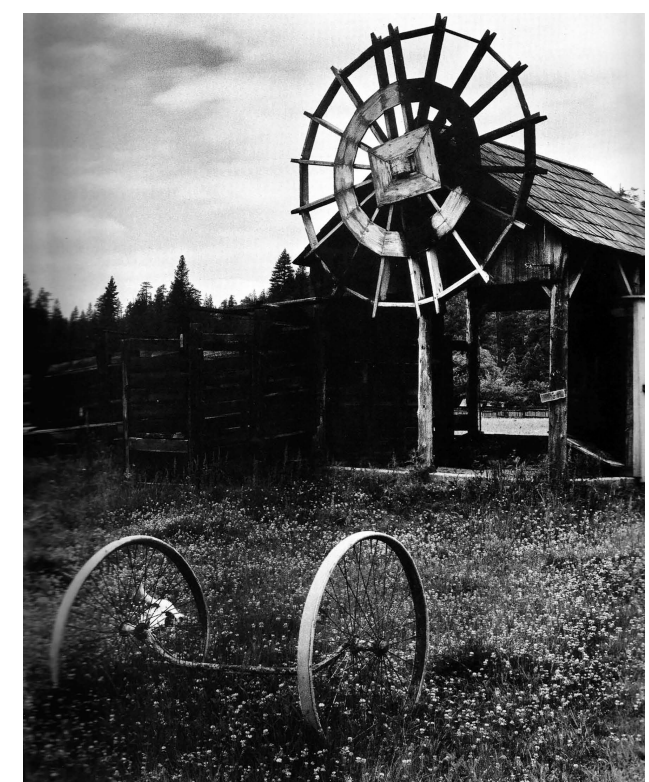

7

Fig. 6. Fotograma de Stagecoach de John Ford (1939), con el territorio del oeste encumbrado por el director, Monument Valley.

Fig. 7. Edward Weston, "Meyer's Ranch" (1938)

(En WILSON, Charis y Edward WESTON. California and the West. Aperture, New York, 1978. (C) Edward Weston).

24. Juan Antonio Ramírez señala que en los años treinta, edad de oro del cine americano y del género western, todos los grandes estudios iniciaron la construcción de sus propios escenarios del oeste, ya fuese una calle como Warner Brothers, 0 ciudades completas como Universal o Paramount. Véase RAMíREZ, Juan Antonio, La arquitectura en el cine Hollywood, la edad de oro. Alianza Editorial, Madrid, 2003, p. 133

25. Las localizaciones principales de estos films serían los estados de Arizona, California, Colorado, Kansas, Nuevo México, Oklahoma, Texas, Utah y Wyoming

26. La alteración del género no es ni siquiera necesaria para un desplazamiento del lugar, resultando suficiente con que el paisaje identificado refleje de modo adecuada la simbología de la historia. Un ejemplo reciente de ello puede ser la cinematografía de Emmanuel Lubezki para The revenant (2015), película que recupera el espíritu del primitivo hombre de frontera de comienzos del siglo XIX, utilizando de modo indistinto escenarios naturales de Estados Unidos, Canadá y Argentina para reemplazar el lugar original de la acción, el entorno del actual Yellowstone National Park.

27. Una buena introducción sintética del concepto, desde el punto de vista histórico, puede encontrarse en POMEROY, Earl S. The American Far West in the twentieth century. Yale University Press, New Haven, 2008. Desde una perspectiva complementaria, véase CAMPBELL, Neil, The cultures of the American New West. Fitzroy Dearborn Publishers, Chicago, 2000.

28. El trabajo de Weston dará lugar en 1940 al libro WILSON, Charis y Edward WESTON, California and the West. Aperture, New York, 1978; que redefine y amplia el carácter del paisaje del oeste entonces popular.

29. LEVINE, Lawrence W., "The Historian and the Icon. Photography and the History of the American People in the 1930s and 1940s" en FLEISCHAUER, C., y BRANNAN, B., Documenting America, 1935-1943 (Approaches to American Culture), University of California Press, Berkeley, California, 1988, p. 28. 
Fig. 8. Algunas imágenes, sociales y territoriales, del reportaje de LIFE sobre las Dust Bowl. A la derecha, la representación del nuevo pionero, el hombre del oeste americano de los años treinta.

Fig. 9. Dorothea Lange, "The Road West/Highway to the West - They keep the road hot a goin' and a comin'- or -They've got roamin' in their head-. US 54 in Southern New Mexico" (1938). En DURDEN, Mark. Dorothea Lange. Phaidon Press Limited, London, 2011. (C) Dorothea Lange.

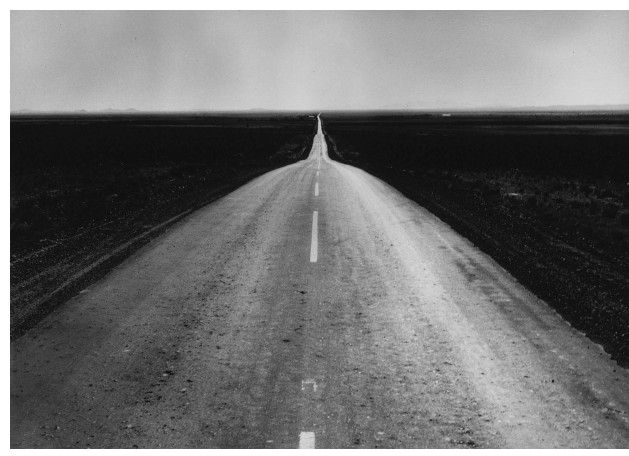

9

30. AGEE, James y Walker EVANS, Elogiemos ahora a hom bres famosos. Editorial Planeta, S.A., Barcelona, 2008.

31. LIFE. "U.S. Dust Bowl", LIFE, 2 (25 (21 June 1937)), 1937, 60-5.

32. Por ejemplo con la realización del libro LANGE, Dorothea y TAYLOR, Paul, An American Exodus: A Record of Human Erosion. Yale University Press, New Haven, 1969. La publicación puede enmarcarse en una serie de proyectos destinados a la sensibilización de la población urbana menos afectada po la crisis, verdaderos destinatarios de este mito reconstruido.

33. Paul S. Taylor, citado en DURDEN, Mark, Dorothea Lan ge. Phaidon Press Limited, London, 2011, p. 84. Esta relación entre emigración, paisaje y mitos ha sido ampliamente abordada en MITCHELL, Don, The Lie of the Land. Migrant Workers and the California Landscape, University of Minnesota Press, Minneapolis, 1996.

34. En realidad se trataba de un proceso no muy diferente que había tenido lugar ya en el siglo XIX tras la guerra civil momento en el que se produce la primera gran migración de la sociedad agrícola americana en busca de la oportunidad de una vida mejor que, al igual que sucedió en los años treinta muchos no encontraron. La historiadora Carmen de la Guardia recuerda en relación a ello la existencia de un texto cuya presencia se hizo habitual en los carromatos de los emigrantes decimonónicos: "En Dios creímos, en Kansas nos arruinamos" ["In God we trusted, in Kansas we busted"]. Véase DE LA GUARDIA, Carmen, Historia de Estados Unidos, Sílex Ediciones S.L., Madrid, 2012, p. 229.
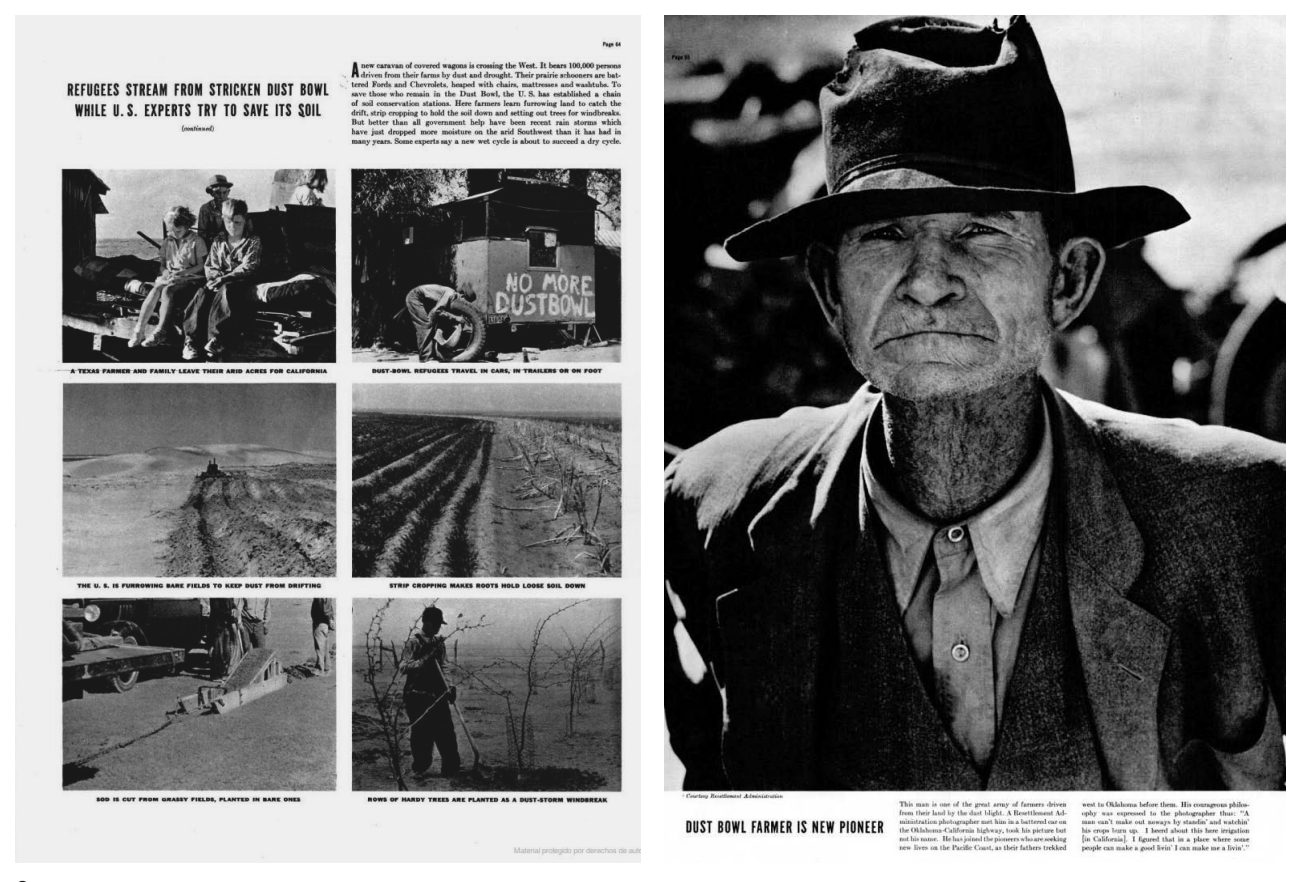

8

"Los americanos de la depresión, viviendo una de las crisis más grandes de nuestra historia, miraban el pasado, y particularmente el pasado folklórico, como un símbolo de pureza y sencillez; como un tiempo menos problemático de vivir, en el que los individuos aún comandaban sus propios destinos y compartían un propio universo de la forma más amplia posible. (...) En la cultura popular de los años veinte se encajó a través de un énfasis en los héroes auto-suficientes de épocas pasadas como el viejo oeste, cuando el bien y el mal supuestamente se distinguían con facilidad y los seres humanos tenían la capacidad de alterar su entorno".

Bajo este renacimiento romántico y nostálgico del oeste se esconde la idea de que en la vida del campo pervivía una dignidad que debía ser motivo de orgullo y contribuir a superar las dificultades de los años treinta. Ese orgullo que, por ejemplo, Walker Evans y James Agee trataron de mostrar en Let Us Now Praise Famous $M^{30}{ }^{30}$, pero que también tuvo su reflejo en una dramática nueva conquista del oeste, la vinculada a los procesos migratorios desde los arruinados campos hacia esa nueva tierra de oportunidades que era California. Una peregrinación que fue mostrada ya no solo por organismos oficiales como la Farm Security Administration, sino también por la prensa popular, como ocurrió con un reportaje de la revista LIFE de 1937, titulado U.S. Dust Bowl ${ }^{31}$ en el que, en el marco del desastre económico, social y ecológico que supuso dicho fenómeno, no deja de ensalzarse, mediante una fotografía de Dorothea Lange intencionadamente reencuadrada, al agricultor inmigrante como la representación del nuevo pionero americano (Fig. 8.).

La idea de este pionero del nuevo oeste guarda una relación con los hechos de la Gran Depresión no muy diferente a la que la figura del vaquero tenía con la conquista de la frontera, porque ambas no dejan de ser construcciones artificiosas del mismo mito cultural aunque se sitúen en contextos espaciales e históricos diferentes. El profesor de economía agrícola de la Universidad de Berkeley, y uno de los mayores especialistas de la época en la documentación de los efectos de las Dust Bowl sobre el campo americano, Paul Schuster Taylor ya evidenció esta disfunción entre el nuevo oeste ideal que estaba siendo comunicado y la realidad, a la que él mismo había contribuido ${ }^{32}$, afirmando que "el Nuevo Oeste, esta 'nueva frontera' no responde, una vez transformada por la mecanización agrícola, a ninguno de los mitos románticos. La única oportunidad que espera a quien viaja allí es la de un empleo temporal en un mercado laboral desorganizado" 33 . Lo que no evitó que buena parte de esas comunidades agrícolas empobrecidas se adentrasen en esa nueva "conquista del oeste"34, en la búsqueda de un lugar en el que recuperar un modelo de sociedad y economía que parecía perdido.

En esta nueva imagen del oeste, si un viejo campo arrasado por la maquinaria agrícola como el retratado por Dorothea Lange en Tractored Out (1938) representaba la crítica hacia la modernización y la industrialización, y las fotografías de los modos de vida de aparceros y emigrantes, como las ofrecidas por Walker Evans en Let Us Now Praise Famous Men, 

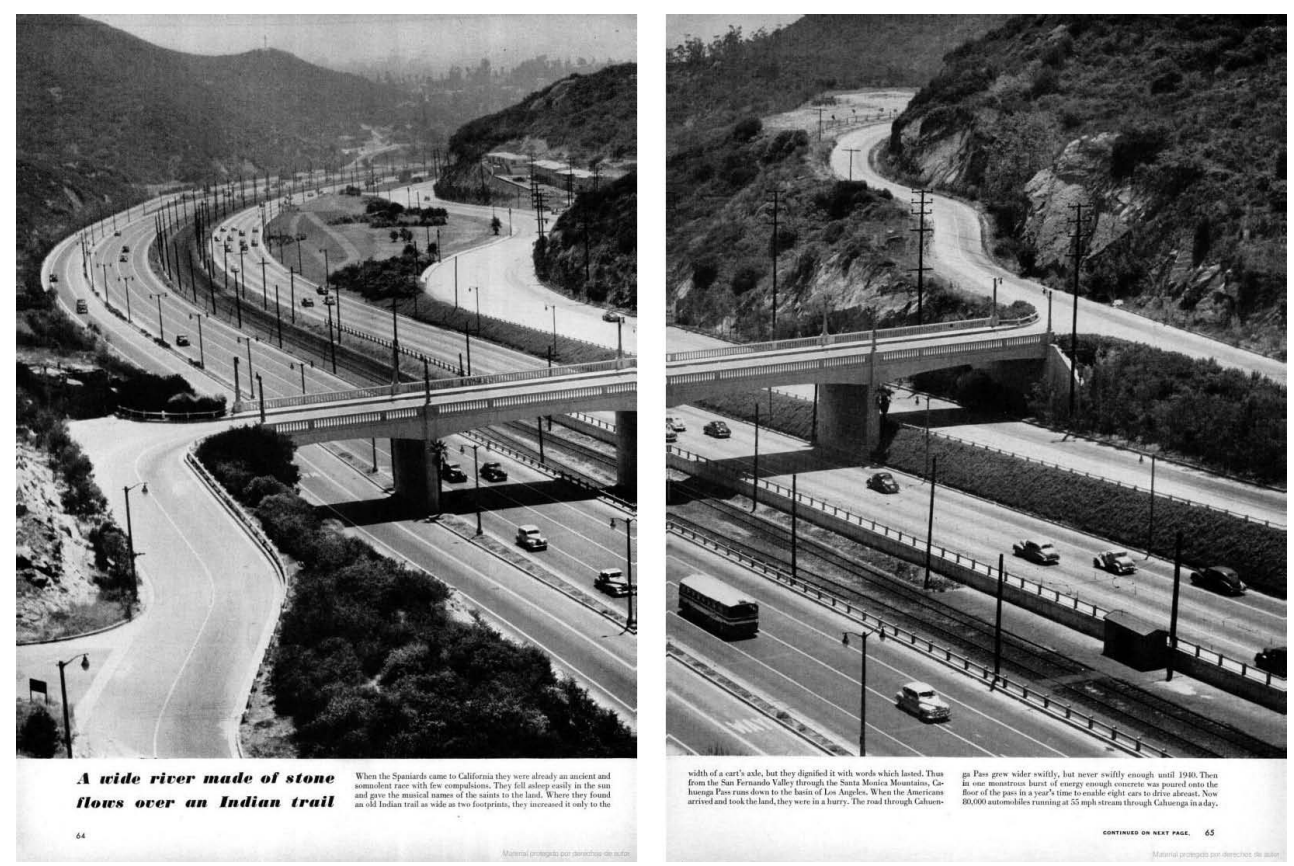

Fig.10. La carretera como el "río hecho de piedra" en el nuevo oeste.

trataban de ofrecer la imagen admirable de una sociedad tradicional, un elemento territorial específico estaba comenzando a ser entendido como símbolo de esperanza. Este no será otro que aquel que iba a marca a partir de entonces buena parte de la identidad territorial americana: sus carreteras (Fig. 9).

\section{EL RENACIMIENTO DEL NUEVO OESTE}

En las décadas de los cincuenta y sesenta el universo del oeste fue revitalizado gracias a un elemento que se convertiría en parte esencial de un renovado American Way of Life, la televisión, una ventana al mundo, real pero también mítico, que se abría a todo americano desde la comodidad del hogar. En ella, una sucesión de películas ${ }^{35}$, series de número creciente e incluso una publicidad encabezada por la icónica figura del hombre Marlboro creada en los años cincuenta por Leo Burnett, lograron que el mito histórico, pero también territorial y social, no solo se mantuviese presente en el imaginario estadounidense sino que el mismo siguiese teniendo sentido más de un siglo después de los hechos que le dieron origen. El relato del oeste seguía representando un conflicto victorioso entre la civilización y lo salvaje, el de la superación de las dificultades y el control y ocupación del territorio. Pero si en el siglo XIX esta ocupación era realizada por granjas vaqueras, ahora parecía estar comandada por una creciente clase media suburbana que, al igual que los primeros, estaban creando un nuevo espacio, material y social, de frontera.

Asimilar que la naturaleza y el nuevo modelo suburbano o, de modo más generalizado, todo el territorio construido por el hombre, pueden desempeñar la misma función dentro del mito no resulta tan extraño en el marco de una cultura como la estadounidense. De hecho, en el año 1948 el fotógrafo Andreas Feininger ya había ofrecido una versión temprana de esta analogía en un reportaje para la revista Life con el título "Man-made landscapes" 36 en el que las carreteras o las torres petrolíferas de sus fotografías eran descritas como "un ancho río hecho de piedra" o "un bosque hecho por el hombre" (Fig. 10). El subtítulo del artículo no podía ser más elocuente, destacando que, en cinco generaciones, "los americanos habían cambiado el aspecto del oeste" ${ }^{37}$, construyendo un oeste propio, adaptado a sus necesidades.

La verdadera formalización consciente de ese nuevo nuevo oeste, y el descubrimiento de la nueva frontera americana, tendrá lugar sin embargo ya en la década de los setenta, gracias a una joven generación de fotógrafos fascinados precisamente con aquello de lo que ya había hablado Andreas Feininger, la coexistencia de un radical cambio material de ese territorio

35. No debe olvidarse que una cuarta parte de todas las películas producidas en los Estados Unidos hasta los años sesenta habían sido westerns. Véase ENGELHARDT, Tom, $E$ fin de la cultura de la victoria Estados Unidos la guerra fría y el desencanto de una generación. Paidós, Barcelona; Buenos Aires; México, 1997, p. 55.

36. LIFE. "Man-made landscapes. American have changed the face of the West", en LIFE, 25 (1 (5 July 1948)), 1948, 63-81. 37. Ibid. 
Fig. 11. Robert Adams, "Mobile Homes, Jefferson County, Colorado" (1973). (En ADAMS, Robert. The New West Landscapes Along the Colorado Front Range. Walther König, Köln, 2000. @ Robert Adams).
38. LONGWELL, Dennis, Photographs by Henry Wessel, JR (October 3 - December 15, 1972). Press Release. Museum of Modern Art, New York, 1972

39. JENKINS, William, New Topographics: Photographs of a Man-altered Landscape, The International Museum of Photography at George Eastman House, Rochester, NY, 1975. La exposición fue reproducida, por primera vez en Europa, en 2009, publicándose un nuevo catálogo crítico, SALVESEN, Britt y Alison NORDSTRÖM, New Topographics, Steidl, Göttigen, 2009.

40. ADAMS, Robert, The New West: Landscapes Along the Colorado Front Range, Walther König, Köln, 2000.

41. "El oeste suburbano es, desde una perspectiva moral, la deprimente evidencia de que hemos abusado de nuestra libertad". Robert Adams, citado en GREEN, Jonathan, American Photography. A Critical History 1945 to the Present, Harry N. Abrams, Incorporated, New York, 1984, p. 168.

42. Ibid.

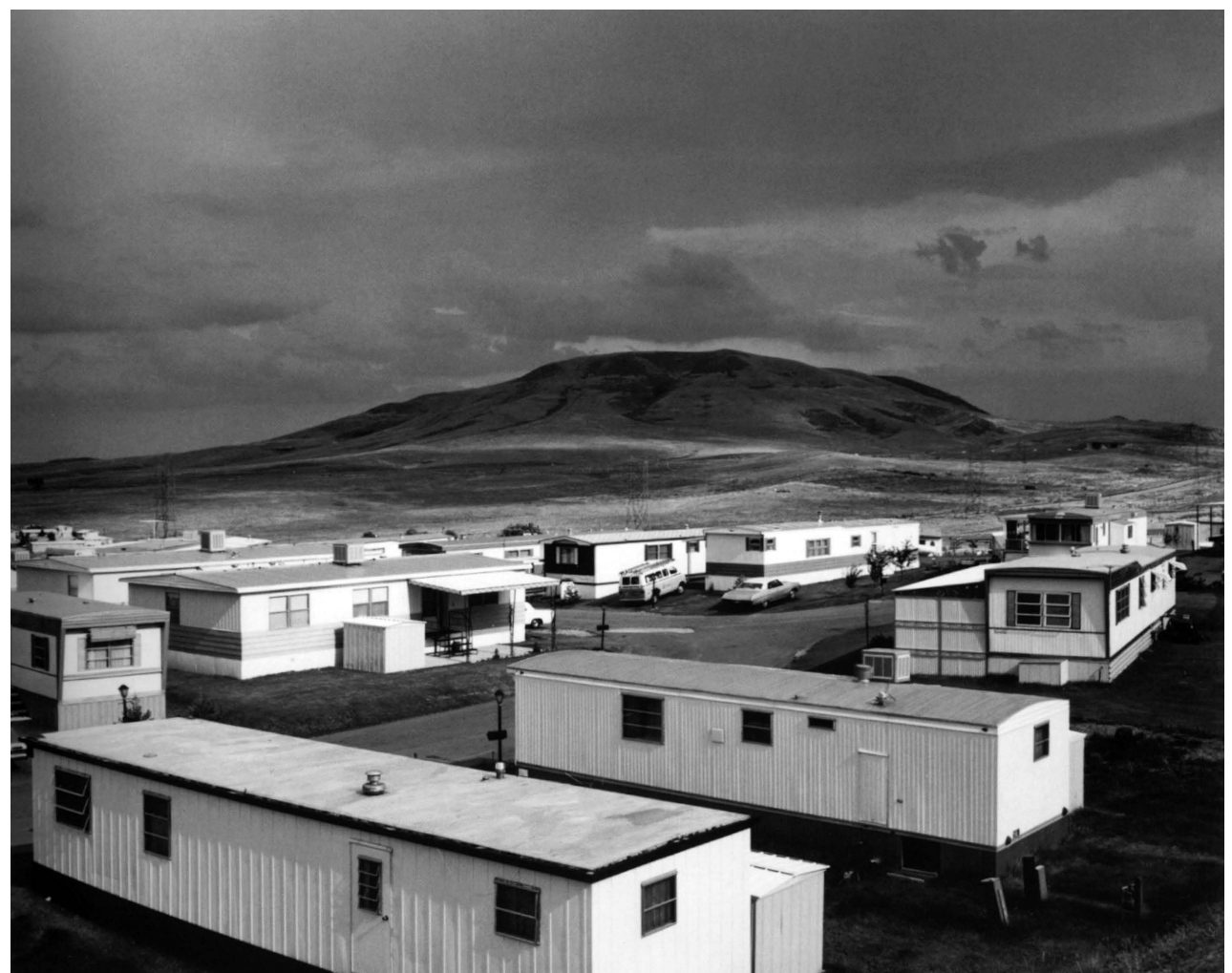

norteamericano con una capacidad de preservación de su condición simbólica. Esta dualidad se encontraba además muy en sintonía con las intenciones de estos modernos fotógrafos que ya no entendían sus imágenes exclusivamente como documentos de la realidad o como arte, sino que pretendían conscientemente hacer de ellas repositorios y transmisores de conceptos, algunos de los cuales no eran muy diferentes a los que ya habían querido comunicar algunos de los pioneros en el arte de la fotografía americana.

Esta equiparación se hizo patente, por ejemplo, en la exposición que el MoMA dedicó a un joven Henry Wessel Jr. en 1972, cuya nota de prensa establecía por primera vez una clara analogía, que en los años sucesivos se hará habitual, entre los fotógrafos decimonónicos y esta nueva generación, para terminar afirmando que sus imágenes estaban enseñando "cómo es la apariencia actual del oeste" 38 . La reconocida exposición New Topographics de $1975^{39}$, cuyo título no hacía sino evocar precisamente a aquellos primeros fotógrafos encargados de levantar un acta documental y visual de los territorios explorados durante el siglo XIX, no hizo sino reafirmar esta posición, convirtiendo lo que hasta entonces eran solo acercamientos individuales y heterogéneos al tema del paisaje americano de posguerra en un movimiento con entidad propia, pero también con un encuadre cultural preciso. El propio Wessel participaría en esta muestra con un trabajo acerca de la diversidad de la arquitectura residencial americana, aunque quién de modo más consciente apostó entonces por una nueva visión del oeste sería Robert Adams (Fig. 11), a través de algunas fotografías de su The New West: Landscapes Along The Colorado Front Range ${ }^{40}$.

El nuevo oeste de Adams, que con el de sus contemporáneos ha tenido una influencia indudable en nuestra percepción actual del paisaje norteamericano, e incluso en el nacimiento de géneros cinematográficos como el neo western, es, en esencia, la representación de lo mismo que el viejo oeste, de una fricción entre mundos, entre civilización y naturaleza, manifestada sobre un territorio. Es una reinterpretación, imperfecta, distorsionada y, como él mismo señalaría también, moralmente criticable ${ }^{41}$, del mito del oeste, de una búsqueda del contacto con la naturaleza y, al mismo tiempo, de los conflictos derivados del deseo humano de conquistar y dominar la misma. Pero en el fondo, en esa aparente ruptura formal de los cánones del paisaje, y también de la sociedad que el mismo refleja, existen más invariantes y continuidades de las que superficialmente parecen mostrarse, porque "por encima de las casas baratas y la basura uno ve en ocasiones una luz tan clara como aquella capturada por [Timothy] O'Sullivan"42. 


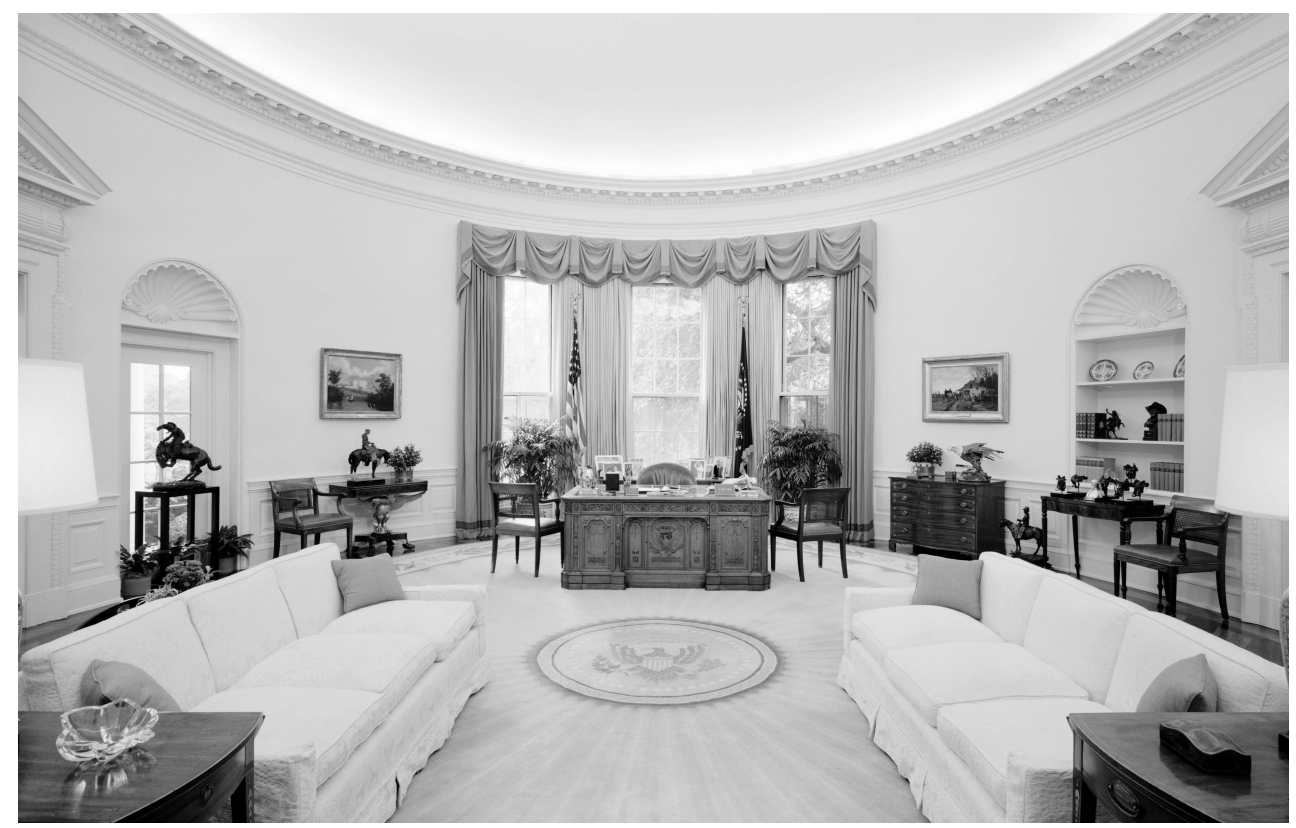

\section{LA BÚSQUEDA DE UN SENTIDO ACTUALIZADO DEL OESTE}

El final del oeste como realidad histórica supuso el inicio de una dilatada trayectoria del oeste como mito, que quizá haya sido social y territorialmente más influyente que los propios hechos que lo sustentaron. La extraordinaria flexibilidad del mito ha permitido la adaptación del mismo a diversos contextos hasta convertir lo que inicialmente tenía únicamente una condición de divertimento en un lugar de encuentro que permite, al mismo tiempo, comprender el mundo de un modo culturalmente específico y hacerlo avanzar en una determinada dirección. Lo que resulta invariante es que, sea cual sea el sentido en que este se aplique, reproduciéndolo o cuestionándolo, el territorio siempre ocupa un lugar central y protagonista en su definición.

Esta relevancia de lo territorial resulta evidente en sus construcciones de ficción. Howard Hawks decía que toda historia del oeste debía estar asociada a un paisaje, y que los únicos westerns malos eran "aquellos en los que se cuenta una historia que podría suceder en cualquier lugar"43. En la realidad el vínculo ha permanecido, pero el sentido, en cierta medida, se ha invertido. Ante un hecho territorial cualquiera, ya sea la naturaleza, el campo o lo urbano suburbial, el mito del oeste ha posibilitado en numerosas ocasiones la articulación de una narrativa simbólica mediante la cual asimilarlo o incluso proponer cómo actuar sobre él.

A lo largo del pasado siglo XX, la imagen ha cobrado una particular importancia en este proceso de construcción del relato, erigiéndose como un mecanismo fundamental para la comunicación de ideas espaciales, particularmente cuando el objeto puede ser conceptualmente asimilable pero materialmente inalcanzable por el observador. Como se señalaba también en la presentación de la exposición de Henry Wessel Jr. para el MoMA, las fotografías, ya fuesen las del siglo XIX o las del XX, nos mostraron la apariencia del oeste "de un modo análogo a como las imágenes de los astronautas nos cuentan cómo es la Luna" ${ }^{44}$, como una verdad a la que debemos dar credibilidad pero que nunca podríamos verificar a través de nuestra propia experiencia. Y aun así, todas ellas fueron capaces, a través de la creación simultánea de un imaginario visual y una narrativa para el mismo, de movilizar determinadas reacciones ante esos territorios por parte de una sociedad siempre receptiva a esos estímulos.

Conocer, de modo retrospectivo, el papel que el mito del oeste jugó en la configuración no solo de determinados paisajes sino también de unos determinados modelos de sociedad es una labor compleja pero que puede ser abordada, como han hecho historiadores como Earl S. Pomeroy ${ }^{45}$. Describir, desde una perspectiva geográfica o arquitectónica, las características de los nuevos paisajes americanos a través de la mitología de la frontera resulta también una labor de notable interés, quizá más por su trasfondo social que por el estricta-
Fig. 12. Jack E. Boucher, "Oval Office; White House, 1600 Pennsylvania Avenue, Northwest, Washington, District of Columbia, DC" (ca. 1990). (Library of Congress Prints and Photographs Division Washington, D.C., HABS DC,WASH, 134-176).
43. Citado en ASTRE, Georges-Albert y HOARAU Albert-Patrick, El universo del Western, Fundamentos, Madrid, 1997, p. 22

44. LONGWELL, Dennis, Photographs by Henry Wessel, JR (October 3 - December 15, 1972). Press Release, Museum of Modern Art, New York, 1972.

45. POMEROY, Earl S., The American Far West in the twentieth century, Yale University Press, New Haven, 2008. 
46. Algunas esculturas, como The Bronco Buster (Frederic Remington, 1895), situada en la imagen frente a la ventan izquierda, han permanecido ininterrumpidamente en el Despacho Oval desde que fuera regalada al presidente Jimmy Carter, siendo reproducida incluso en las recreaciones cinematográficas de este espacio. mente espacial. Pero lo que resulta aún esquivo es comprender si existe o no un motivo u oportunidad, más allá de una simple moda, para un moderno renacimiento del interés por el western que ya no se restringe ni al ámbito de la ficción ni al contexto espacial y cultural estadounidense, sino que ha trascendido definitivamente sus primitivos límites. Quizá dentro de algún tiempo logremos entenderlo, o quizá nos demos cuenta de que realmente no existe tal renacimiento, sino que el oeste, como realidad y como mito, como forma de pensamiento y forma territorial, nunca ha dejado, de algún modo, de acompañarnos, condicionando una parte de lo que sucede a nuestro alrededor (Fig. 12) ${ }^{46}$. Nuestro acercamiento al mito puede ser hoy, como en el pasado, solo un mecanismo que nos ayuda a contextualizar y asimilar algunos de estos hechos, pero también un primer paso para una comprensión que quizá pueda contribuir a cambiarlos.

Carlos Santamarina-Macho. (Giijón, 1981) Arquitecto por la Universidad de Valladolid (Premio Extraordinario Fin de Carrera, 2005), master en Restauración Arquitectónica (2007) y doctor en Urbanística y Ordenación del Territorio (2016) por la misma universidad, con la tesis "Cultura y representación del man-made landscape. La construcción de la imagen de un territorio: EE. UU.; 1925-1975", realizada bajo la dirección de Juan Luis de las Rivas Sanz. Actualmente compagina la docencia en el Departamento de Teoría de la Arquitectura y Proyectos Arquitectónicos con la actividad profesional vinculada a la planificación urbana y territorial. 